\title{
Supporting the Small-to-Medium Vessel Industry
}

\author{
Nikos Frangakis, Stefan N. Grösser, Stefan Katz, Vassilis Stratis, \\ Eric C.B. Cauchi and Vangelis Papakonstantinou
}

\begin{abstract}
The aim of this chapter is to present a methodology for supporting the collaboration between the involved parties and for augmenting the final product with an always up to date digital file. The methodology is based on three support tools, which focus on the life cycle of small craft passenger vessels made of composite materials. The chapter concentrates on FRP (Fibreglass Reinforced Plastics) made vessels with length overall up to $30 \mathrm{~m}$ and total capacity up to 150 passengers, for the purposes of cruise ship liners disembarkation, scheduled routes or transportation of professional personnel to offshore sites. The collection of proposed tools consists of the "Vessel Meta-File", a user-friendly, web-based, information rich, technical meta-file that acts as the main knowledge-base between the ship-yard, which is the constructor of the vessel, the classification society, which is the controlling body imposing the restrictions of the vessel and the end-user. The Vessel Meta-File enables the storage of information regarding all
\end{abstract}

\author{
N. Frangakis $(\bowtie)$ \\ I-SENSE Research Group, Institute of Communication \\ and Computer Systems, Zografou, Greece \\ e-mail: nikos.frangakis@iccs.gr \\ S.N. Grösser · S. Katz \\ Institute for Corporate Development, Bern University of Applied Sciences, \\ Bern, Switzerland \\ e-mail: stefan.groesser@bfh.ch \\ S. Katz \\ e-mail: stefan.katz@bfh.ch \\ V. Stratis \\ OCEAN Boatyard Company OE, Attica, Greece \\ e-mail: vstrat@ocean.gr \\ E.C.B. Cauchi \\ SEAbility Ltd., Athens, Greece \\ e-mail: sea@seability.eu \\ V. Papakonstantinou \\ International Naval Survey Bureau, Piraeus, Greece \\ e-mail: vagelispapakon@gmail.com


aspects of a vessel's life cycle; from initial customer requirements, to drawings, material and equipment data, sea-trial reports to post-delivery survey and inspection reports. The Vessel Meta-File provides a collaborative platform for sharing such data among all involved actors across the vessel's life-cycle, reducing costs involved in the design, production and maintenance phases. The proposed methodology introduces the use of two additional tools which can be used in conjunction to the Vessel Meta-File. First, a Dynamic Causal Context Model that describes the mechanisms and variable interactions between the Yard, the Classification Society and the end-user, and enables the three different parties to forecast trends in the behaviour of the small craft passenger vessels market and allow predictive actions and decisions such as the upgrade of a vessel to support and extend its life-cycle. Second, a "Vessel Configurator" system is also proposed to assist the transformation of the business and operational requirements derived from the Dynamic Causal Context Model to technical specifications that comply with current national flag or international regulations for the specific type of vessels.

Keywords Naval sector - Small vessels • Business models • System dynamics • Communications $\cdot$ Computational simulation

\section{Introduction}

\subsection{Introduction of the Cluster Case and the Respective Cluster/Company Challenges}

The aim of this chapter is to present a methodology, based on three support tools, which focus on the life cycle of small craft passenger vessels made of composite materials. The chapter concentrates on FRP made vessels with Length Overall up to $30 \mathrm{~m}$ and total capacity up to 150 passengers, for the purposes of cruise ship liners disembarkation, scheduled routes or transportation of professional personnel to offshore sites.

The collection of proposed tools consists of the "Vessel Meta-File", a user-friendly, web-based, information rich, technical meta-file that acts as the main knowledge-base between the yard, the classification society and the end-user. The Vessel Meta-File enables the storage of information regarding all aspects of a vessel's life cycle; from initial customer requirements, to drawings, material and equipment data, sea-trial reports to post-delivery survey and inspection reports. The Vessel Meta-File provides a collaborative platform for sharing such data among all involved actors across the vessel's life-cycle, reducing costs involved in the design, production and maintenance phases.

The proposed methodology introduces the use of two additional tools which can be used in conjunction to the Vessel Meta-File; a System Dynamics Model (Groesser 2012a) that describes the mechanisms and variable interactions between the Yard, 
the Classification Society and the end-user, and enables the three different parties to forecast trends in the behaviour of the small craft passenger vessels market and allow predictive actions and decisions such as the upgrade of a vessel to support and extend its life-cycle. A "Vessel Configurator" system is also proposed to assist the transformation of the business and operational requirements derived from the Dynamic Causal Context Model (see Groesser, Chapter "Complexity Management and System Dynamics Thinking") to technical specifications that comply with current national flag or international regulations for the specific type of vessels.

The Cluster's main actors include (a) the ship yard: OCEAN, (b) the classification society: INSB and (c) the end user representative: SEAbility. Below each actor is described in more detail framing its activities around the Vessel information rich-Meta file.

OCEAN is essentially a boat manufacturing company which specializes in building work boats and passenger vessels made of composite materials. The company is based in Greece, a country with numerous islands and economic activity related to tourism. As with other Greek boat manufacturing companies, OCEAN has its roots in production of coastal fishing boats for professional use. Although production of professional fishing boats is still a major boat market sector for countries like Greece, focusing on product-markets related to tourism and efficient sea-water transportation is essential in times where local economies and demand are hit by global recession. Using its past reputation for tough, over-engineered professional boats, over the past years OCEAN has invested efforts in specializing in passenger vessels for all purposes but mainly tourist transportation. As any other manufacturing process involving complex products, boat manufacturing involves marine specific materials, parts, conformity to marine specific regulations, design patterns, etc. For this purpose, OCEAN is working within a network of marine professionals and marine related companies: Equipment vendors representing foreign manufacturers, local equipment manufacturers, material manufacturers, technical consultants and certification bodies (Shipping Registers or Classification Societies). Each of these companies brings its expertise, experience and innovation into the final product. The boatyard's task is summarised as the effort to use and concentrate the best options offered by this "network of companies" in order to satisfy customer-specific requirements.

INSB is a non-governmental ship classification society active in the international maritime industry. It promotes ship safety standards by providing customers with reliable technical services for their ships and marine installations, while cost leadership and quality compliance (Certified by ISO 9001: 2008) are embedded in every aspect of its operations. INSB provides proper certification to vessel, according to national and international laws and regulations. Through a sound organisational structure and technically competent human resources, it enjoys worldwide confidence on the part of all major maritime stakeholders. INSB operates internationally via a well-structured expanding network in 50 countries with 6 regional offices, 60 field stations, 200 ship surveyors and auditors supported by professional staff, able to respond timely and effectively in Europe, Asia, Africa and the Americas-wherever ships are being built, repaired or operated. INSB Class aims to be a preferred global technical provider of risk management solutions, enhance its customers' quality 
orientation and environmental and business performance. Safety for life and property at sea, quality, sustainability and immense responsibility for environmental protection are the bedrock of INSB's corporate mission. INSB business deliverables and technical services satisfy internationally-recognised safety and quality standards, IMO Conventions, national requirements and general EU criteria.

SEAbility is a private Greek SME, specialising in representing shipping lines, performing vessel port operations as well as consulting to Shipping and Transport Lines. SEAbility is proficient in all aspects of Containerised as well as of RoRo (Roll-On/Roll-Off, as in e.g. ferries, where loading and discharging of wheeled vehicles takes place horizontally) and conventional shipping. It is especially strong in vessel port operations, Logistics and Cost Management, ship operations and efficient handling. Its activities include managing sea transportation services and adding value to them through well-trained and motivated team members interacting with an advanced IT environment. At the same time, it is a consultant to Shipping Lines on issues regarding their introduction to new markets, the handling of their fleet and of their services. These issues comprise operational, scheduling, financial, environmental and marketing aspects and optimisation whilst also taking into account and evaluating possible synergies with existing services loops (of the same shipping line or other lines), aiming at economies resulting from scale and also from scope.

\subsection{Connection to the UIW-Challenge in Part I}

Via the development of a single rich-metadata file the consolidation of the shipbuilding process, better management of costs and improved maintenance planning, Use-it-Wisely (UIW) will be able to offer extended lifecycle and improved post construction survey and certification processes, hence costs reduction in EUR and environmental costs.

Improving certification of existing and new passenger ships is achieved through the reduced consideration time and approval in accordance with national regulations and any amendments thereto. The digitisation of the relevant law is combined with the initial configuration request of the owner of the vessel and allows the owner to take more informed decisions on the type of the vessel needed and allowed. Two steps will provide the improvement: (1) Standardisation of requests and (2) Combination of the consideration and the rules in conjunction with their amendments and application in the standard requests.

Moreover, unification of standardisation will aid increasing productivity. Decreasing review times and approvals, the time of final certification is reduced, so the society becomes more efficient in handling requests by the owners and the ship owning companies of passenger vessels up to $30 \mathrm{~m}$ in length overall and passenger capacity of up to 200 passengers. Improved response times, minimise decision time for shipbuilding and rebuilding by the owners therefore produce more efficient passenger ships "decreasing the operational cost" (lighter ships $=$ decrease in fuel consumption), or possible increase in capacity or a combination thereof. To 
elaborate more on how each actor benefits from the overall achievements of the UIW-challenges:

Customers will be able to:

- View the final outcome as a whole from day one

- Make decisions based on visualised scenarios which will include information such as physical properties and cost

- View and visualize any change or update

- Track changes during any stage of production or use of product.

The boatyard will be able to:

- Offer and quote to customers with virtual models of the final product

- Make proposals, estimate costs regarding material and parts

- Conform with specifications, rules, guidelines

- Optimize designs

- Validate manufacturing procedures and processes

- Validate changes of design, materials and parts

- Track changes and updates

- Communicate the project and its properties to vendors and subcontractors.

The Classification Society will be able to:

- Offer to the customers an automated consultation tool

- Keep track of the legislation and its changes

- Follow the modifications to the vessel and their conformity with legislation

- Have an overview of previous approved solutions to offer to customer.

\subsection{Reasons to Select the Tools}

The tools (vessel meta-file application and vessel web configurator) selected to facilitate the communication between the actors are mostly web-based, so as to enable the modern cloud-based approach of software and also to enable various approaches of exploiting their usage, namely software-as-a-service (Dubey 2007). Moreover, business modelling for analysis and prediction has been used for informed decision making and thus it was logical to use such tools for long-lived products, such as vessels.

\section{Tools and Solutions}

\subsection{Development Process}

The objective of the Cluster 5 model is to link business activities to the objectives of individual market actors and show their impact on the UIW-objectives. To achieve that, individual models for SEAbility, OCEAN, and INSB have been built. Each 


\begin{tabular}{|c|c|c|c|c|c|c|c|c|c|c|c|c|}
\hline \multicolumn{10}{|c|}{} & \multicolumn{10}{|c|}{2015} \\
\cline { 2 - 24 } & Jan & Feb & Mar & Apr & May & Jun & Jul & Aug & Sep & Oct & Nov & Dec \\
\hline Seability & LS & LS & LS & HS & HS & HS & HS & HS & HS & LS & LS & LS \\
\hline OCEAN & HS & HS & HS & HS & HS & HS & LS & LS & LS & HS & HS & HS \\
\hline INSB AR & LS & LS & LS & HS & HS & HS & HS & LS & LS & LS & LS & LS \\
\hline INSB NR & HS & HS & HS & HS & HS & HS & LS & LS & LS & LS & LS & LS \\
\hline
\end{tabular}

Fig. 1 High season (HS) and low season (LS) for each actor $(A R=$ annual requests, NR = new requests)

model was extensively validated on the level of system structure and behaviour (Groesser et al. 2012). The individual models were subsequently linked together to form the Cluster 5 industry-model. The industry model is driven by the demand from the tourism market which is strongly seasonal. The operators buy boats and try to optimize the purchase so that the boats are ready for service at the beginning of the high season (SNAAM 1985). This is reflected in the model with yearly oscillation patterns for all market actors in customer demand; i.e. tourists for SEAbility, boat orders for OCEAN and INSB respectively. The yearly high season and low season periods for the market actors are shown in Fig. 1.

The touristic high season for operators in Greece typically spans from April to September inclusive, of each year. This means that prior to the period when cruise ships with tourists start their schedules to Greece, the boats have to be operational and to achieve this the boats are built between October and June of each year, a period which represents the high season for the boatyard OCEAN. It is important to note that in the model operators tend to target April for boat delivery times and rather restrictive towards early and late boat deliveries, meaning that they postpone the purchase to the next year, resulting in strong peaks in the purchasing behaviour in the simulation results. Annual requests for INSB are occur between February and July so as to ensure that the boats are ready for that year's operation, while new requests for boats run parallel to the construction of boats and result in a high number of new requests for INSB between January and June.

\section{Results}

\subsection{System Dynamics Model}

\subsubsection{Overview of the Integrated Industry Model}

The elements of the integrated industry model.

The industry model consists of the three individual models for the market actors which are complemented by a market model simulating the market behaviour of 


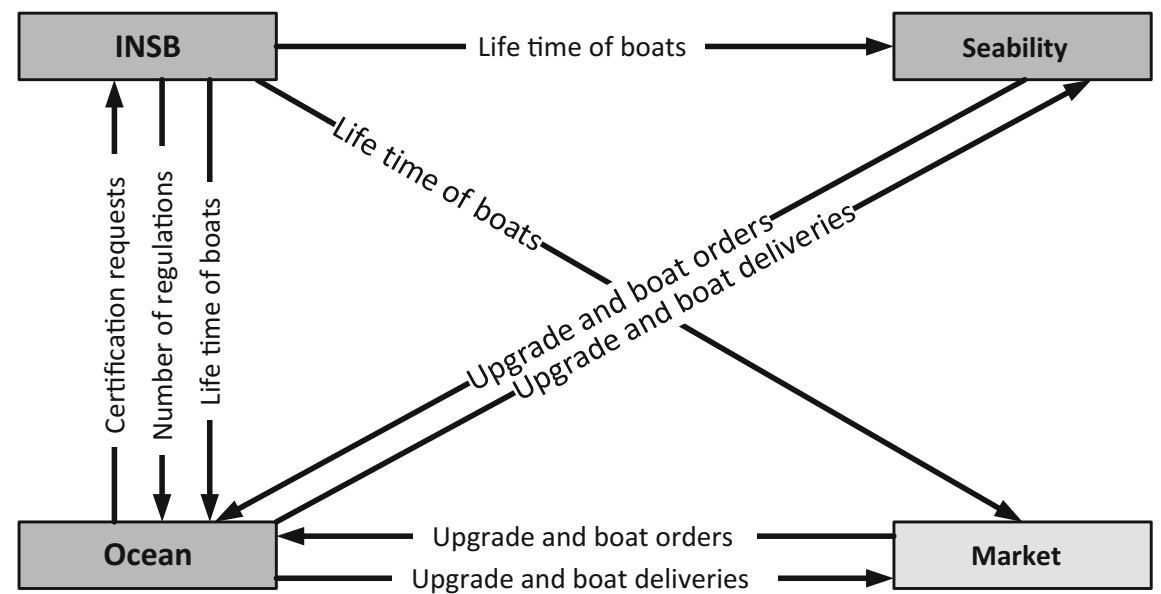

Fig. 2 Sector diagram for the integrated industry model

SEAbility's competitors. Figure 2 shows the major information flows of the industry model. Due to the size of the model and the number of connections between the individual models, only the most relevant information flows are displayed (for a further example of this approach see (Groesser 2012b). INSB's impact is mostly through the setting of boundaries and constraints such as boat lifetime, i.e. the time that a boat is allowed to operate, which will be evaluated in the policy analysis. Furthermore, INSB identifies the number of changed regulations and that information is passed on to OCEAN. OCEAN sends the certification requests which INSB then handles. In addition, OCEAN receives the boat-building and/or upgrade orders from SEAbility and the market, which in turn lead to construction of boats which are then delivered to the respective operators. The relevant market is divided in two parts (Fig. 3), "All other markets", representing the overall tourism-related shipping demand with the exception of Santorini, which is modelled separately as Santorini is the area of operation for SEAbility.

All operators for the market have a decision making structure similar to that of SEAbility, but base their decisions uniquely on the high season, whereas SEAbility also includes low season factors in its decision-making process. Furthermore it is assumed operators always have the financial means to buy boats when it is necessary.

The market in Santorini is depicted to grow as shown in Fig. 3, while the other market are assumed to be constant at 1.8 million passengers per month. The individual models for the three market actors INSB, OCEAN, and SEAbility are described in more detail below.

INSB is the certification society in charge of managing the changing regulations and certifying both boats in operation as well as new buildings. For the purpose of the model, the impact of INSB on the entire model is rather small. The certification 


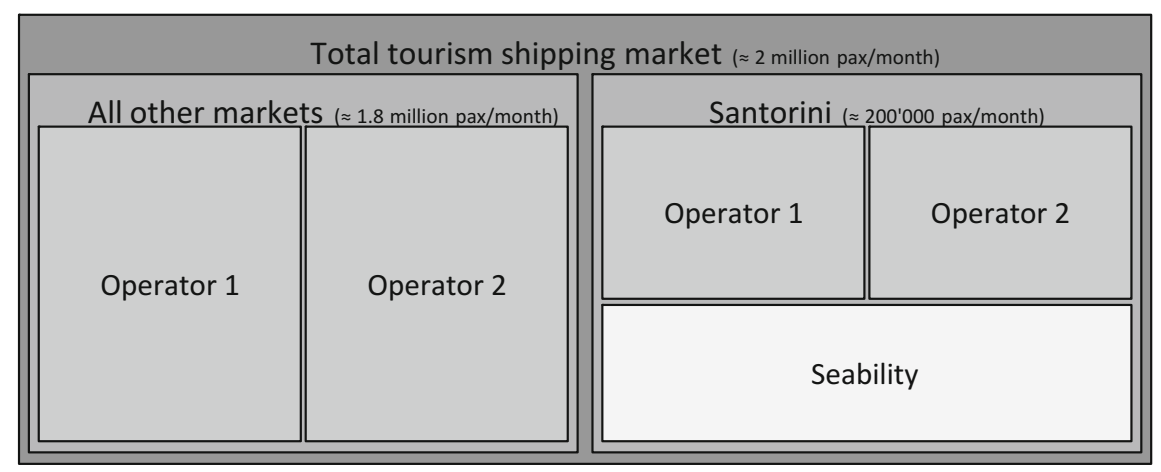

Fig. 3 Elements of the market, SEAbility competes for customers in the Santorini market, pax/month means passengers/month

society adds a delay when it comes to the construction of the boats through the checking of the boat's design. INSB's importance in the model is in setting the framework for boat operation such as the total time a boat can be used, which we will evaluate in the policy section. One of the most important features of a classification society is to ensure that boats are kept in order and designs for boats are safe. However, for the purpose of this model, individual boat designs have not been modelled and thus this role has no impact in the model. It is assumed in this model that all boat designs are approved. The certification role of INSB is limited to certifying each new construction and the annual certification of each boat. This delays the construction of the boat and removes the boat from use in the low season, which is only applicable to SEAbility.

The structure in Fig. 4 shows the different steps that have to be taken before a new request is complete and is certified. The first two steps "guidance" and "survey" are done during the construction of a boat while the latter two "consideration" and "certification" are done upon completion of the construction of a boat, thus extending the boat construction time.

Figure 5 shows the behaviour of handling time for new requests (left) and allocated capacity for new requests (right). INSB's business consists of two separate elements: The annual requests (AR) and the new requests (NR). The annual requests happen during the entire low season when boat operators do not operate their boats (with the exception of SEAbility) while new requests peak towards the end of the low season when boat operators want to put their newly purchased boats to service. This leads to peaks in handling time as seen on the left and peaks in allocated capacity as seen on the right. The boat construction business is cyclical and there are periods without boat construction. However, INSB cannot anticipate that and still provides capacity that then is then underutilised.

OCEAN is the boatyard in this cluster. The company is an important player in the industry, having a market share of $80 \%$ in passenger boats. While OCEAN's 


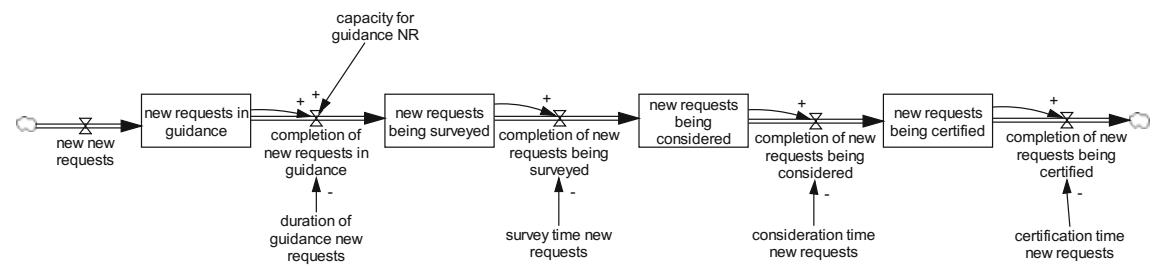

Fig. 4 Essential structure of the INSB model: handling of new request
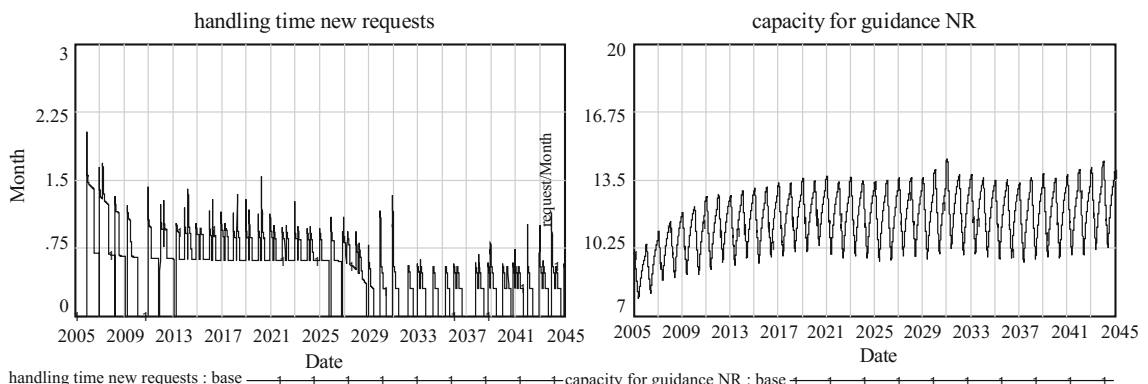

Fig. 5 Essential behaviour of the INSB model about new requests

portfolio features a multitude of boat designs of various lengths, for the purpose of the model this portfolio was simplified to comprise two categories, viz. small $(<10 \mathrm{~m})$ and large $(>10 \mathrm{~m})$ boats. To keep the model as simple as possible, newly constructed small boats are used for a single purpose, as utility boats and all small passenger boats have to be converted from utility boats. The resulting difference in the construction of small boats between reality (where only a few small boats are designed as passenger boats) and the model is only marginal and has no impact on the validity of the model results.

OCEAN and its competitors perform three types of boat related services: (1) construction of new boats, (2) conversion of the type of boat, and (3) upgrading of boats. The construction of new boats is the process where a new boat is built from scratch. In the model, this is done for small utility boats and large passenger boats. The construction of a new boat triggers a new request for certification with INSB. The conversion of the type of boat is done by taking the hull of a utility boat and changing the set up to make it usable as a passenger boat. The conversion of a utility boat to a small passenger boat is shorter than the construction of a new boat, but the boat also has a shorter lifetime due to its past use as a utility boat. The conversion of a boat also triggers a new request for certification with INSB. The upgrading of boats does not change their general set up. However, it updates the technical set up of the boat (e.g., efficiency, emissions, attractiveness). 
Upgrading is the shortest of the three services, and does not trigger a new request with INSB as the technical set up of the boat essentially remains the same.

The causal structure shown in Fig. 6 shows OCEAN's building process of large boats. The orders come in from the operators (MARKET and SEAbility) and the construction is prepared. Then, the boat is constructed and released to the market. OCEAN experiences the same purchasing behaviour with strong peaks as INSB since the operators try to optimize their purchasing behaviour by having the boats delivered and operational just before the start of the high season.

The construction time for boats are varies and depends on their size (Fig. 7). For small boats the construction time starts at around 4.75 months and decreases slightly to around 4.25 months. This decrease is due to the implementation of the UIW tool (shown in the following chapters) and a reduction of changes in regulations. For large boats, the building time increases from 5.25 to nearly 8 months. This is due to the fact that the average size of large boats is assumed to increase steadily, hence longer construction times. However, the increase is softened by the implementation of the UIW tool for improved communication between the boatyard and the certification society, with the time savings shown in Fig. 19. In Fig. 7, the dotted line is the planned construction time while the solid line shows the actual construction time. The graph shows how the implementation of the UIW tool in 2015 significantly reduces the delays from changes and regulations (from about 0.5 months to a few days) by comparing the planned construction time (dotted line) to the actual construction time (solid line). The purchasing behaviour of the operators of the boats results in large oscillations in the utilisation of OCEAN's

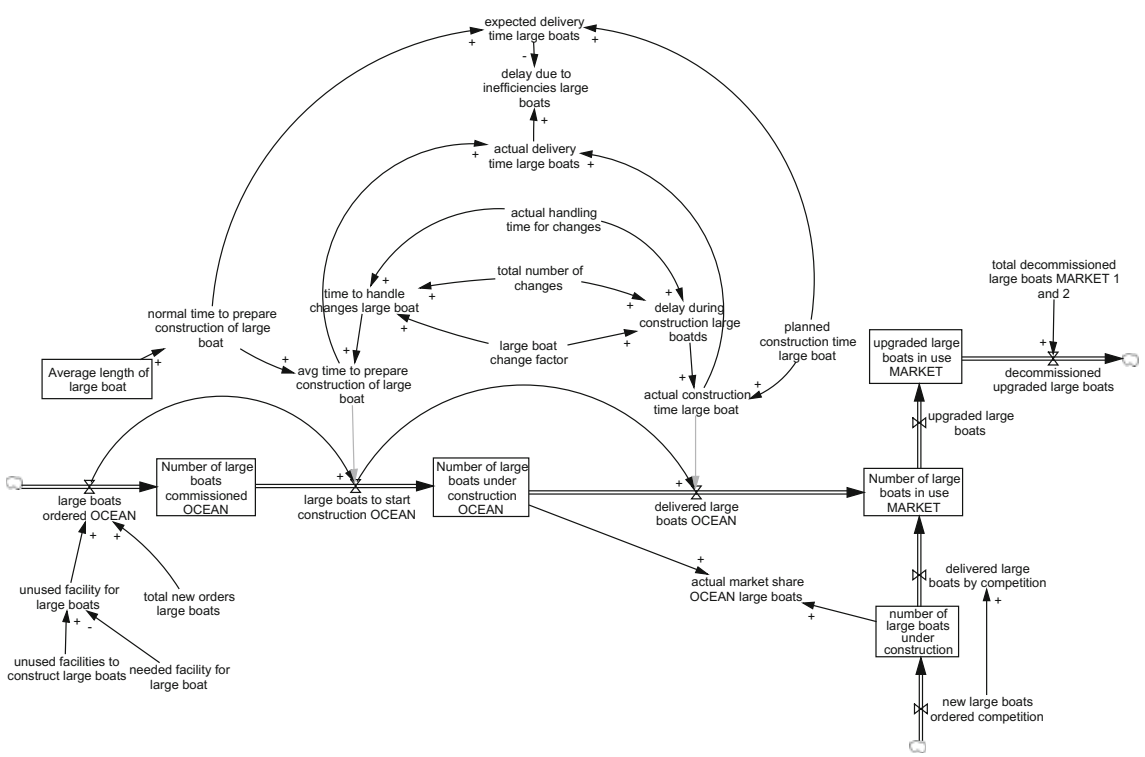

Fig. 6 Structure for building large boats 


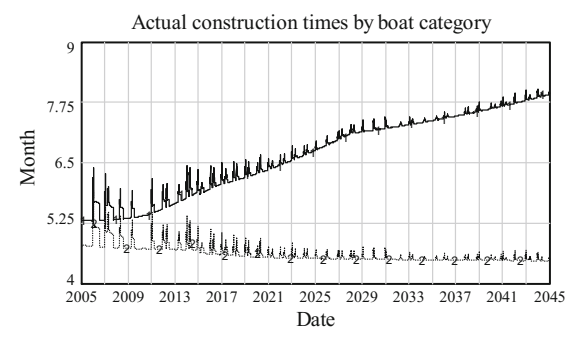

actual construction time large boat : base actual construction time small boat : base

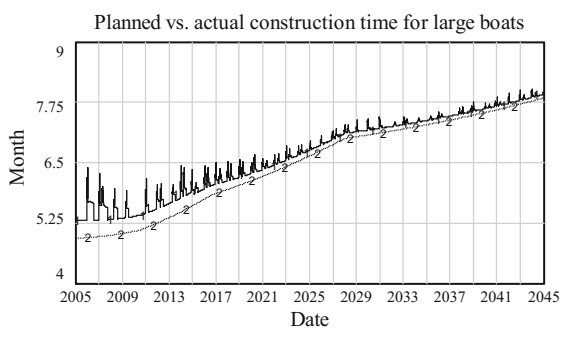

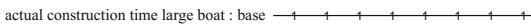

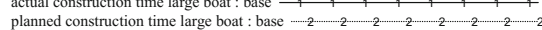

Fig. 7 Essential behaviour of important indicators for OCEAN
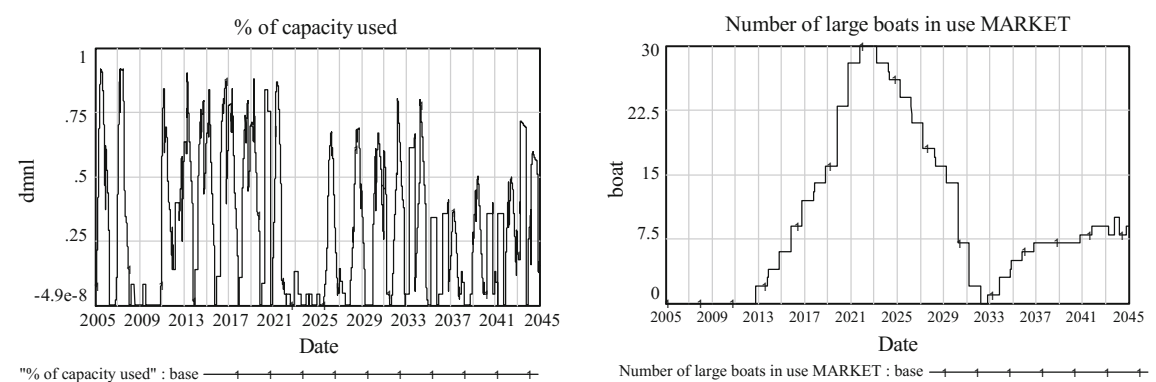

Fig. 8 Short term cycles in large boat construction (left) and long term business cycles for OCEAN (right)

capacity. In addition to short term oscillations, OCEAN also experiences long term oscillations in the construction of large boats (Fig. 8, right side). The solid line shows the number of large non-upgraded boats in use in the entire industry. The first period of construction of large boats is from 2013 to 2021, during which 30 large boats are built. Between 2021 and 2032 all of these boats are upgraded (and thus are not counted in this variable anymore), whilst new large boats are built after 2033.

SEAbility represents the operator side in the industry model. Passenger boat operators in Greece mainly operate in the tourism high season and has as a main market the carriage of tourists from cruise ships anchoring at sea near the island harbours to the islands' disembarkation ports and back. SEAbility operates in the market of Santorini, but the essential market and operator dynamics are assumed to be the same for all operators. Other elements of the business model for operators can be additional local boat tours for the tourists that are in the islands (having arrived at the islands both by cruise ships and otherwise) as well as low-season services (e.g., ambulance, longer transport routes, postal), however, only SEAbility has included these services in its model. Operators use a variety of boats for their 
services. Some boats are converted sail or fishing boats and some are newly-constructed boats. With their demand for boat construction, the operators fuel the business of the other actors. To model this more in-depth, the model features an extensive decision-making structure based on demand and current market share for all operators. There is a bias for large boats in the market as the purchasing decision for large boats has to be made prior to the purchasing decision for small boats as the larger boats take longer to be constructed, if the boats are to be operational at the start of the high season.

The business objective for boat operators is to have sufficient boats profitably to cover the demand. Operators have the choice to build small or large boats (Fig. 9). The newly-built boats subsequently age and become less attractive to tourists and more costly to operate. Eventually and after operating for their entire allowed usage time, the boats are decommissioned, leading to replacement purchases if demand warrants this. For the large boats, the operators have the opportunity to upgrade the boat thus leading to an increase in attractiveness and decrease in operating costs.

In the model, SEAbility starts operation in 2015 in the Santorini market, which is expected to decline in customer demand until 2020, followed by recovery. This development is mirrored in Fig. 10 (left) where the demand is sufficient to trigger the purchase a boat in 2015 and 2026 and a second boat in 2037. Interestingly, the boat purchased in 2015 is decommissioned in 2025, leaving SEAbility with no boat for about a year as the decision making by SEAbility is rather conservative and does not allow for the purchase of a boat to replace the existing boat because the demand is insufficient. Utilisation (Fig. 10, right) is below 100\% until 2025, indicating that there are overcapacities in the market that linger until 2026, when demand has picked up sufficiently and capacity is adjusted.

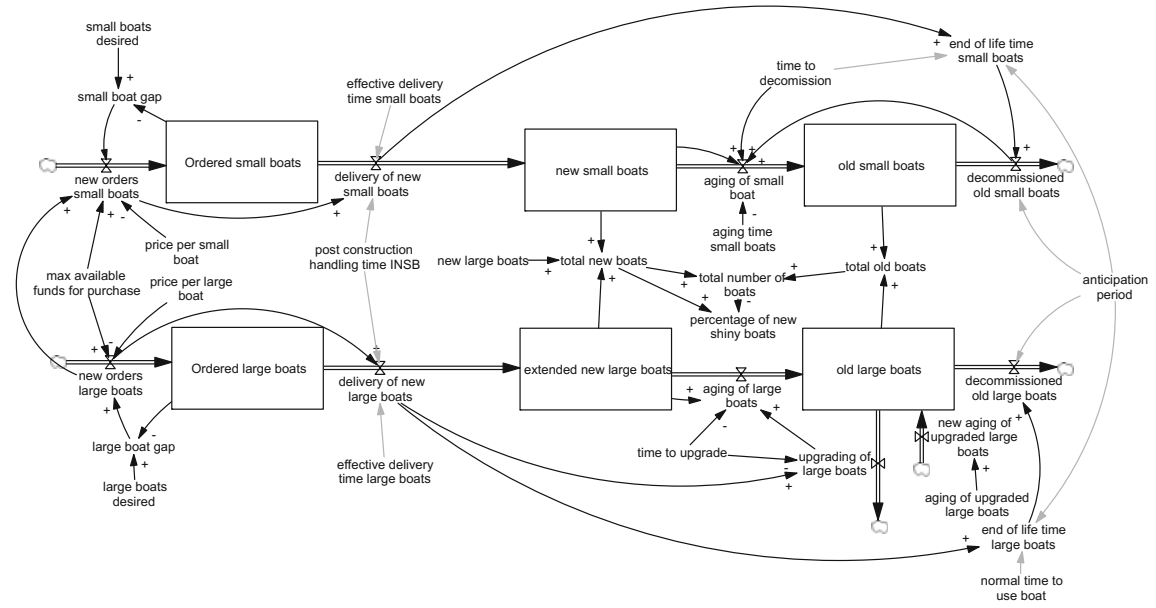

Fig. 9 Fleet composition for operators (using SEAbility as example) 

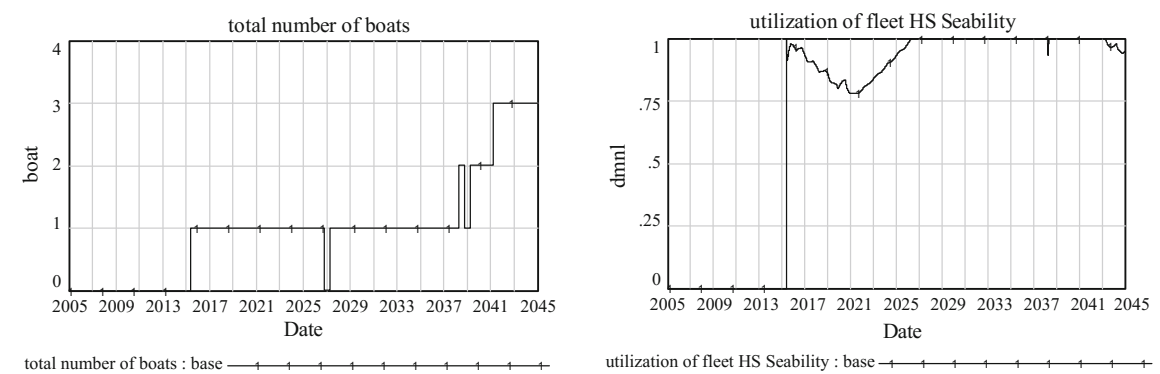

Fig. 10 Essential behaviour for SEAbility, showing the entire fleet for SEAbility (small and large boats)

\begin{tabular}{|c|c|c|c|}
\hline & \multicolumn{2}{|c|}{240 months (base) } & 120 months (base) \\
\hline Large boats & \multicolumn{2}{|c|}{ Normal boat life time } & Extended life time \\
\hline Small boats & Time utility boats & Time to use small boats & \\
\hline
\end{tabular}

Fig. 11 The different lifetimes in the model

\subsubsection{Policy Analysis with the Integrated Simulation Model}

Policy description and results.

The evaluated policy is one set by INSB for the entire industry in terms of the lifetime of the boat. INSB regulates the normal boat lifetime and it is assumed that the extended boat lifetime is always $50 \%$ of the normal boat lifetime (Fig. 11). The extended boat lifetime can be achieved by upgrading large boats. As small boats cannot be upgraded, their life span is entirely defined by the normal boat lifetime. The operational lifetime of small boats is further decreased by the fact that in the model all small boats are converted utility boats and can only be used for the remaining lifetime of the boat. To capture the effects of the boat lifetimes, the time horizon for the simulation has been set to 480 months (forty years) with ten years simulating past behaviour and thirty years simulation time into the future (measured from the base year of 2015).

For the policy analysis of the boat lifetime there are two policies simulated in addition to the base case shown in Fig. 11. The policy "boat lifetime 204" (LT204) simulates the effects of 204 months normal lifetime and 102 months extended and "boat lifetime 276" (LT276) with the values of 276 months normal lifetime and 138 months for extended. The simulated policies show the effects, if INSB chooses to reduce or extend the permissible use time for boats by three years.

As can be seen in Fig. 12, OCEAN profits from a reduced boat lifetime. LT204 (dotted line) performs better nearly throughout the entire simulated period. This can be expected because with a reduced boat lifetime operators need to replace their boats sooner and this leads to more boat orders. Interestingly however the runs only start differing in 2023. The available facilities (i.e., production capacity) stay 
roughly the same for all scenario until 2033, so the improved financial result after 2023 is mainly due to a better utilisation of the available facilities. The comparison between LT276 (dashed line) and the base case (solid line) is also interesting because over large parts of the simulation period, the LT276 run performs better than the base run. This is counterintuitive since a longer boat lifetime result in fewer boat orders. The cause for LT276 to perform better lies in a better distribution of orders during the multi-year cycle. The difference only changes in around 2037 when many of the large boats need to be replaced and since the lifetime of large boats is more sensitive to any reduction or extension of the normal boat lifetime, the effects can be observed more sharply after 2037. Also, in that time there is a strong clustering of orders in the LT276 run prompting OCEAN to expand its capacity sharply. The fact that both policies fare better over most of the simulated period suggests there are local optima for setting the boat lifetime where OCEAN does not lose revenues but the operators have the possibility to maximize their revenues through longer use of their boats. This does not occur in the current base case where the normal boat lifetime is 20 years.

For the operators, however, the effects are mostly opposite. Naturally, the operators would like to maximize their revenue and use the boat as long as possible. The effects of increasing and decreasing the boat lifetime results in a difference of about 1 million euro of cash flow in the case of SEAbility and a larger increase in spending for "Market 1", one operator in the market representing half of the transport capacity of all the other markets (Fig. 13). "Market 1" is used for illustrative purposes, all other operators experience the same effects. The case of SEAbility is interesting because the cash flow for both policies performs better between 2035 and 2045 although the base run eventually catches up. For "Market 1 ", however, the spending on boats is higher for both policies, which should only be expected for the LT204 run. SEAbility profits disproportionately from more frequent replacement of their boats because of the small size of their fleet, which explains the better performance of LT204 and saves more money in the case of LT276. In the case of "Market 1", both policies are more expensive because in LT204 boats have to be purchased more frequently and in LT276 the boats are more evenly distributed allowing the operators to purchase more large boats.
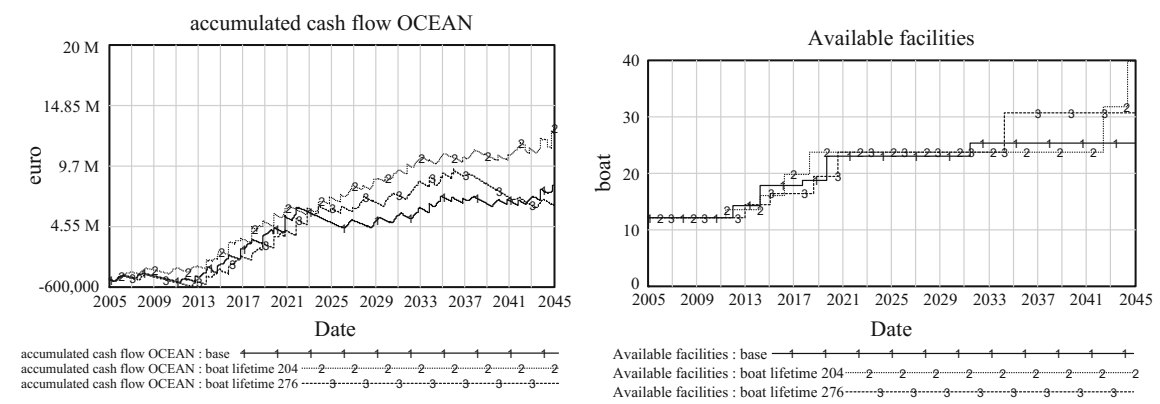

Fig. 12 Effects on OCEAN for the different policies 

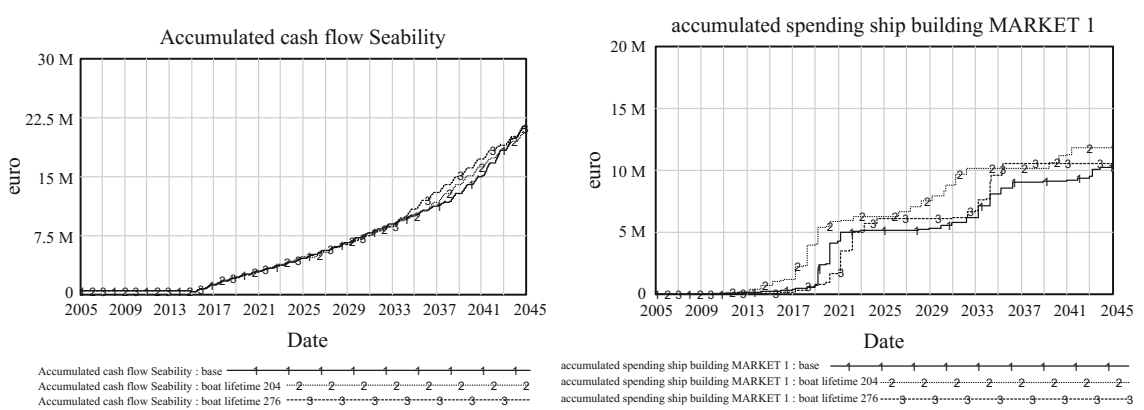

Fig. 13 Effects of the policy on the operators SEAbility (left) and Market 1 (right)

Interestingly enough, one could expect that large boats with their longer lifetime would be subject to greater demand, yet this is not the case; this is mostly because the decision-making does not, for planning purposes, take into account the entire boat lifetime but rather a shorter planning period of five years for strategic decisions. Irrespective of the boat lifetimes, the total demand for the entire market (except Santorini) increases steadily and tops of at 40 large boats for the base run. For both LT204 and LT276 however, the number of large boats increases to around 50 as the boatyard's capacity is more evenly distributed over the years, leading to more purchases of large boats as more capacity is available because boat orders are less clustered.

\subsection{Information Technology Support Tools}

The shipping cluster is using two distinct information technology support tools. A Redmine based communication hub (Redmine 2006), called the vessel meta-file application (Fig. 14).

And a vessel web-configurator, which includes the relevant legislation (MoMM 1979a, b, 1988, 1996, 2011) (Fig. 15).

In the vessel meta-file application, each actor has assigned a specific workflow, which enables the correct transition of the different procedures from one state to another state.

Currently five different workflows exist:

1. Workflow for the conduction of a survey

2. Workflow for the completion of a technical work

3. Workflow for a document request

4. Workflow for an initial configuration of a vessel

5. Workflow for the initial price quotation for a vessel. 


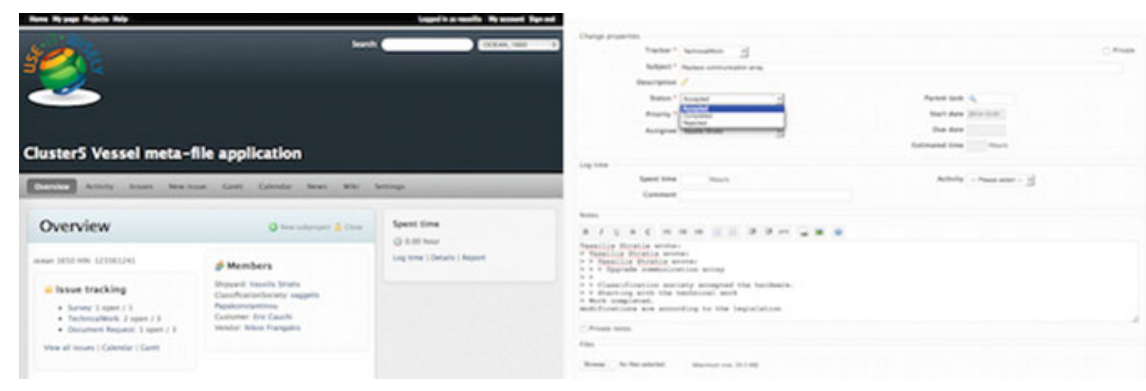

Fig. 14 Vessel metafile application

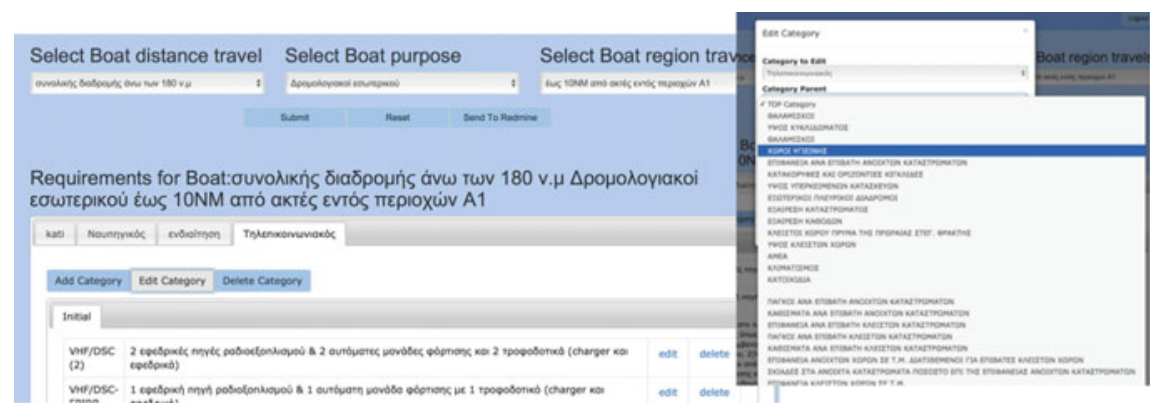

Fig. 15 Vessel web-configurator

Each actor (Shipyard, Classification Society, Customer, Technical Consultant, National Supervisor and Vendor) is assigned a specific workflow to facilitate the verified procedure.

The states of the workflow include:

1. New: the workflow has just started

2. In Progress: currently some actors are actively working on a task

3. On Hold: the task is on hold for some reason

4. Accepted: the task has been accepted by the appropriate actor

5. Declined: the task assignment has been declined by an appropriate actor

6. Completed: the task has been competed

7. Rejected: the task completion has been rejected by an appropriate actor.

For example, the shipyard is able to start a new task "Technical work" and is able to change its status to in progress, on hold, completed or rejected. For the same task, after the shipyard has marked the task as completed, the classification society should check the outcome and mark the task accepted or rejected based on the results of the survey. Moreover, the customer is able to decline this task if the results are not satisfactory (Fig. 16). 


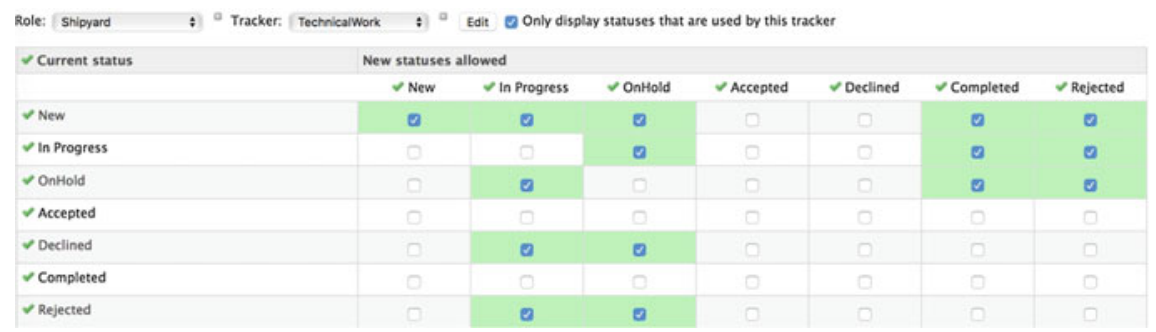

Fig. 16 Vessel metafile application workflow configuration

Similar workflows exist for all the procedures, ensuring transparency to the activities and collaboration of the actors.

The vessel web-configurator enables a future customer to enter the initial requirements into a web system, which then displays a rough overview of the applied legislation (SECP 2000; SoNaME 1990). This enables the future customer to finetune the initial requirements. The legislation is updated by the classification society and covers all the aspects of the vessel.

\section{Discussion}

\subsection{Benefits of Using the Tools}

\subsubsection{Impact of the System Dynamics Scenario on Cluster Objectives}

The objectives for the UIW Cluster 5 scorecard have been set as part of the UIW-project. The objectives have then been subsequently added to the model and the simulated results are compared to the set objectives. As part of the UIW-project, Cluster 5 has also developed a tool to facilitate the communication between the boatyard (OCEAN) and the classification society (INSB) in terms of regulations and amendments of regulations. The tool is only applicable to large boats and only those results are reported. For the simulation, the tool and its effects have been modelled and two runs (one with UIW tool, one without) have been executed. The objective of the UIW tool is a shorter construction time through improved communication which means that its impact is negligible in terms of technological progress (objectives $4 \mathrm{a}$ and $4 \mathrm{~b}$ ) and therefore only the run with the tool active is reported for these objectives (Figs. 17, 18, 19, 20 and 21; Tables 1, 2, 3, 4 and 5).

A system which will integrate past project experience, boatyard's infrastructure and technical ability, vendor solutions and classification society rules into one system which will produce the best possible solution for one customer's business requirements as a dynamic meta-file with possible visualisation of attributes and specifications. Project attributes will be based on future platform's output which could be dynamically changed according to each actor input. Initial requirements 
will be pre-validated by the future platform. Pre-validation will be based on data passed by the Classification society. Selection of specific materials and parts will be based on data passed by vendors and suppliers. Any aspect of initial design or change on initial design will be optimised and checked for compatibility with all

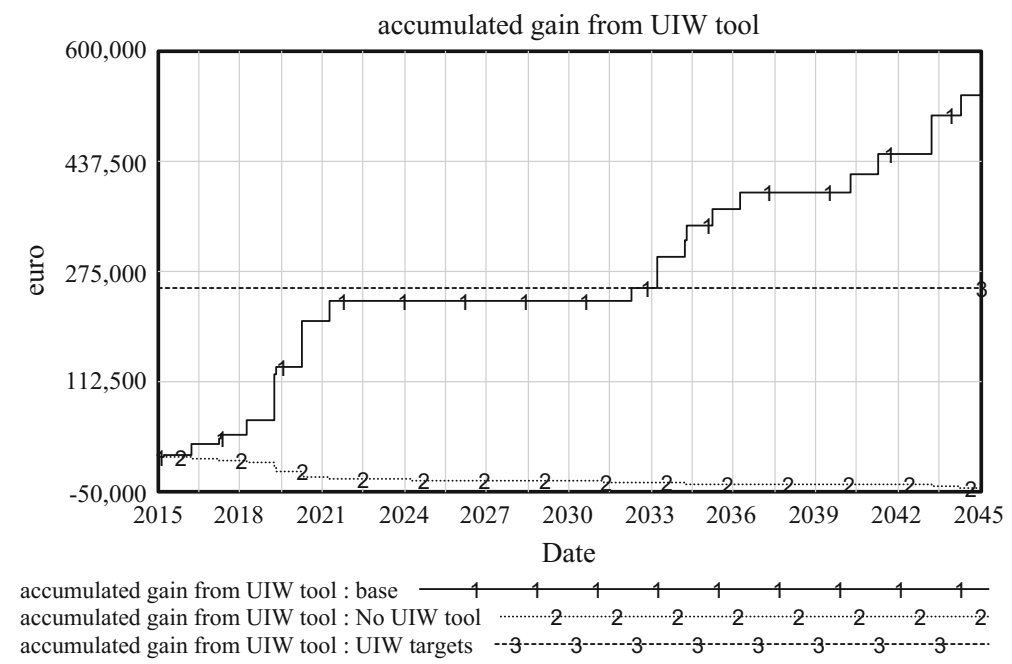

Fig. 17 Graph for gain from UIW tool

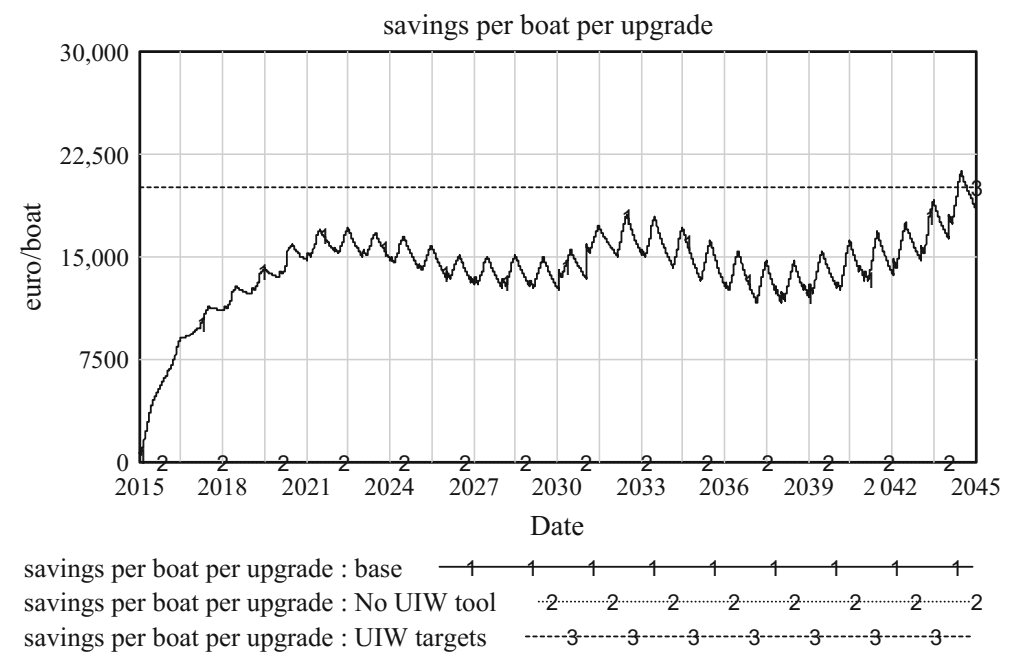

Fig. 18 Graph for savings per upgrade 


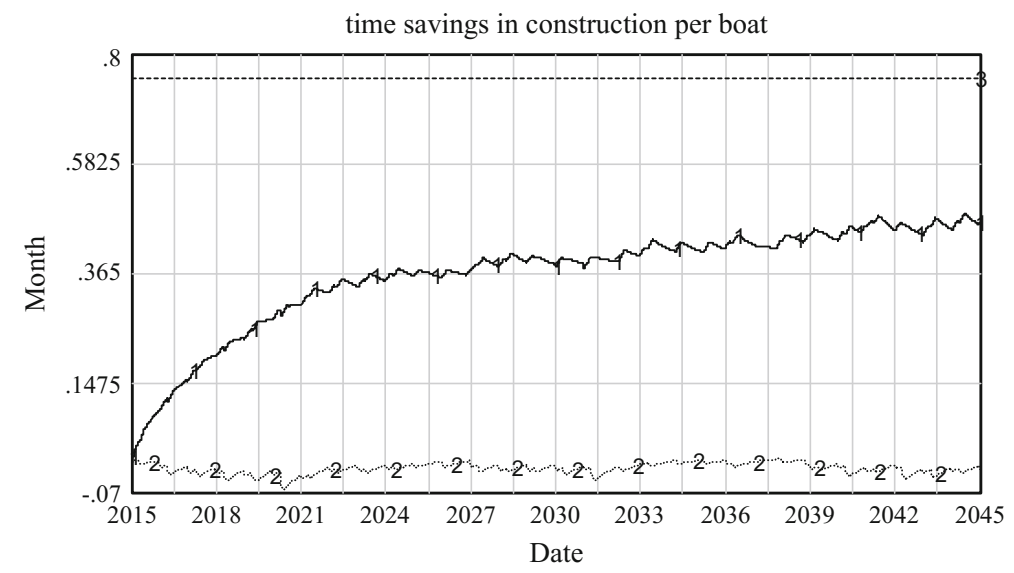

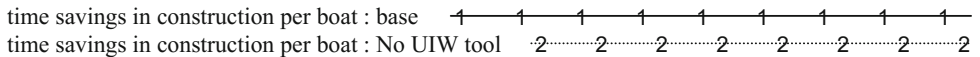
time savings in construction per boat : UIW targets

Fig. 19 Graph for time savings

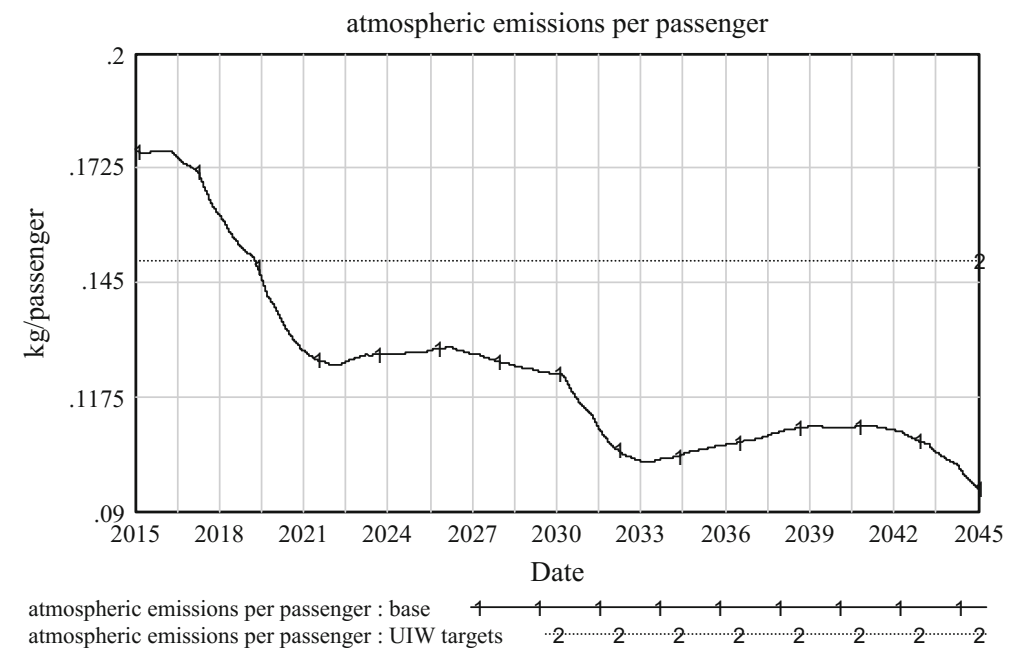

Fig. 20 Graph for atmospheric emissions

actor's specifications. A system acting as a pool of information for all parties would solve the problem of information flow. A system which would integrate properties such as technical specifications, rules, physical attributes, cost, etc. in a virtualised model would solve the problem of optimizing design to dynamic updates and changes. The final result would be a new process of manufacturing where final outcome is based more on initial design than on continuous design cycles. 


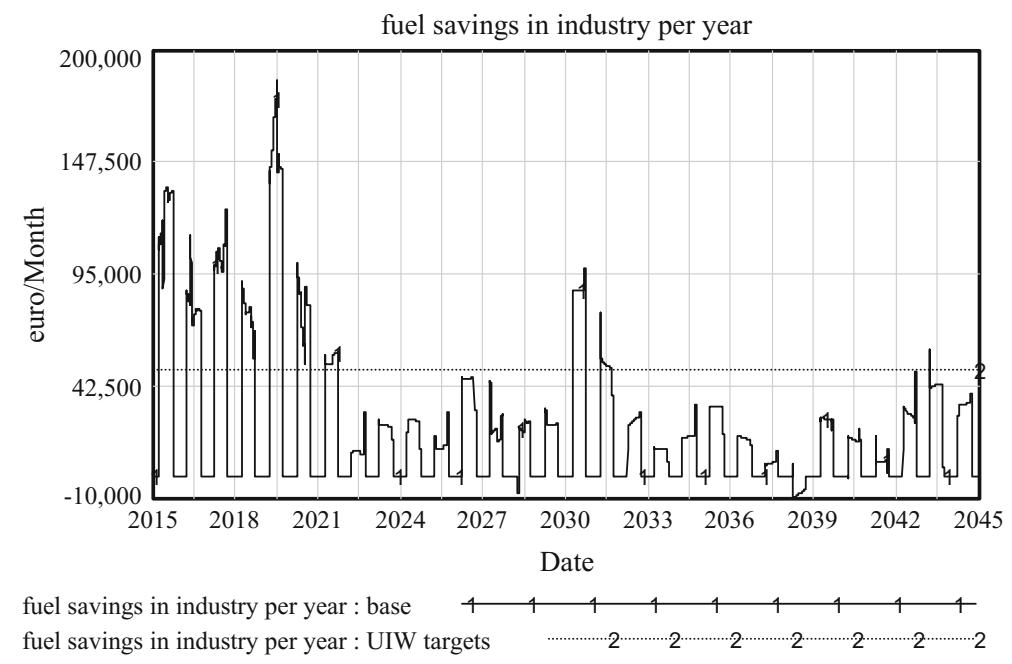

Fig. 21 Graph for fuel savings

The process of deciding on the construction details can be summarised on the following steps:

1. Boatyard decides on materials, based on project requirements (for example cost and weight) and availability from vendors. Material specifications and data sheets are already embedded into the system. Hence, selection is optimised using initial requirements.

2. Calculations regarding material aspects, structural elements and other construction design elements are made by the system, using predefined Classification Rules.

3. A pre-validated construction plan and engineering analysis is produced.

4. Any change or update during the duration of the project dynamically change attributes of the construction plan.

\subsection{Limitations of Using the Tools}

The decision-making of operators is highly individual. Factors such as how aggressively is growth pursued and the timing of the boat purchase depend greatly on how individual operators perceive the market. For the purpose of this model, only one decision-making process is modelled, leading to a reduced amount of richness. This decision-making process can be adjusted for parameters of 
Table 1 Objective 1 of the UIW Cluster 5 scorecard

\begin{tabular}{|c|c|}
\hline Objective & Behaviour \\
\hline Name of the objective: Economic gain from UIW tool & \multirow[t]{3}{*}{ Figure 17} \\
\hline $\begin{array}{l}\text { Objective definition: Increased ability to rapidly follow the market dynamics by } \\
\text { means of fast production and delivery of personalised final products }\end{array}$ & \\
\hline $\begin{array}{l}\text { Cluster-specific objective: Quick reaction to varying service demand, regulation } \\
\text { change, alterations requests from the customer through value chain integration } \\
\text { (€250-300k for the entire industry) }\end{array}$ & \\
\hline
\end{tabular}

Explanation: The graph above shows the target as a dashed line and the simulated result as 1 and 2. The time horizon reported here is from 2015 to 2045 as the tool is not implemented prior to 2015. There are two large boat purchasing cycles. The first one starts in 2015 and lasts until 2020 and the second one starts in 2030. In both periods, a large amount of the operator's transport capacity is replaced with large boats. The economic gain of the UIW tool consists of two parts: (1) The construction of the boat occupies capacity for a shorter period of time as the exchange of technical information between the certification society (INSB) and the boatyard (OCEAN) is improved. Thus, the boatyard can construct more boats during the same building period. (2) The operators (SEAbility) need to commit fewer financial resources with shorter lead times when purchasing a boat and can therefore react better to market trends. The improvement is due mainly to a reduced time to react to changes in the design of boats as well as improvements in handling times for new requests. The target is reached around 2032. Between 2015 and 2030 there are no large boats built and thus no gains from the UIW tool are obtained. The benefit in this objective is measured for the whole industry and accumulated over time The dotted line shows the comparison run in the case that the tool is not implemented. The reference year is again the year 2015 and the effects are accumulated. The "No UIW tool" run shows an accumulated loss for the industry of about 50,000 Euro. This makes sense given that the tool shortens construction times for large boats. This leads to the operators having to make decisions with larger uncertainties about the utilisation of their fleet. This in turn leads to overcapacity in the market. This can be confirmed as the Market 1 as a sample operator uses two more large boats and has a marginally lower utilisation rate over the simulation period in the run without the UIW tool. Therefore, the benefit derived from the improved information exchange and resulting shortening of construction and order times, not only has financial benefits for all actors but also supports an improved use of resources available, e.g., boat materials that are not used for construction

aggressiveness and other factors to more optimally manage an operator's fleet, but it will remain only a guideline on how actual decisions are implemented. Therefore, the market structures are kept as simple as possible. There are just two operators in each market, with the exception of SEAbility being a third, each representing a collection of small operators. The behaviour for many small operators is unlikely to be much different as the model assumes the same decision making process for each operator. Inefficiencies in the purchasing behaviour are, such as an undersupply of available boats, are due to a lack of capacity of OCEAN and of competitors.

Similarly, the topic of upgrading is simplified. For each operator, the upgrading policy can be set individually, but stays uniform for the entire fleet. The operator has no opportunity to change its operating policy from one boat to another. This is obviously a simplification to achieve a manageable model. However, the current 
Table 2 Objective 2 of the UIW Cluster 5 scorecard

\begin{tabular}{l|l}
\hline Name of the objective: savings per boat & Figure 18 \\
$\begin{array}{l}\text { Objective definition: Cost reduction of around } 30 \% \text { by decreasing lead times in } \\
\text { product/process development }\end{array}$ & \\
\hline $\begin{array}{l}\text { Cluster-specific objective: Reducing time and costs by } 30 \% \text { due to the } \\
\text { availability of the vessel technical information (from } € 50-60 \mathrm{k} \text { to } € 40 \mathrm{k} \text { ) }\end{array}$ & \\
\hline
\end{tabular}

Explanation: This objective shows a different aspect of the implementation of the UIW tool. The graph shows the target from the UIW-objective as a dashed line and the result of the simulation as a solid line. The solid line shows the 12 month average for savings in upgrading. While objective 1 concerns the construction of new boats, the implementation of the UIW tool also facilitates and improves the upgrading of existing boats. Upgrading is in general a shorter process than complete construction, as the hull and other elements of the boats remain intact. Regardless, the savings are in the same range as for building on a per case basis. Thus, the tool has a larger impact for the upgrading as it has for building. The objective of $€ 20 \mathrm{~K}$ is achieved towards the end of the simulation period, when the database in the tool includes nearly $90 \%$ of all relevant regulations and amendments. The simulated results oscillate due to the fact that the improved communication between the certification society and the boatyard also depends on the number of amendments. Amendments to existing regulation happen mostly when there are new constructions which in turn take place mostly when fleets are renewed. The renewal of fleets is a cyclical process and causes the oscillating behaviour shown in the graph above

The dotted line shows the run simulating without implementing the UIW tool. In the case of upgrading, no capacity issues are expected to matter and therefore there is no loss to be reported. Thus, the run shows a constant 0

Table 3 Objective 3 of the UIW Cluster 5 scorecard

\begin{tabular}{l|l}
\hline Name of the objective: time savings in boat building & Figure 19 \\
\hline $\begin{array}{l}\text { Objective definition: Set-up and ramp-up time reduction for new processes and } \\
\text { plant designs (30\%) }\end{array}$ & \\
\hline $\begin{array}{l}\text { Cluster-specific objective: Decreased lead time in product modifications by at } \\
\text { least } 20 \% \text { (from ca. } 90 \text { to } 70 \text { days) due to better information about the }\end{array}$ & \\
modifications costs needed to meet new business demands &
\end{tabular}

Explanation: Time savings from the implementation of the UIW tool are shown in the objective above. The target (dashed line) is never reached by the simulation result (solid). This is due to the fact that the initial goal was set for larger boats. Larger boats have longer lead times and changes in the design take longer to be amended. In the case of large boats in the simulation, its result shows a reduction of lead times of nearly half a month. The improvement after the implementation of the UIW tool is initially steep as more and more new requests comply with the system and flattens out after around 2021 when the smaller improvements are due to a decrease in amendments necessary in the regulations. The dotted line shows the "No UIW tool" run and shows a small negative time saving of around three days. This is due to the increased construction of boats and the creation of occasional bottle necks for new requests at INSB. The bottlenecks are corrected rather fast and therefore the run is always very close to 0 
Table 4 Objective $4 \mathrm{a}$ of the UIW Cluster 5 scorecard

\begin{tabular}{l|l}
\hline Name of the objective: emissions per passenger (part a of the 4th objective) & Figure 20 \\
\hline Objective definition: Reduction of around $40 \%$ in the environmental footprint & \\
and resource consumption during the production and use phases of the meta & \\
products, together with an increased use of more environment-friendly materials & \\
Cluster-specific objective: Ability to consider environment-friendly materials & \\
that could expand the life cycle of the product while decreasing the environmental & \\
footprint due to better forecast and planning (reduce atmospheric emissions to less & \\
than $0.15 \mathrm{~kg}$ per passenger per voyage) &
\end{tabular}

Explanation: This objective describes the decrease in emissions due to the use of new materials and technologies. The graph shows the emissions per passenger transported. This is calculated under the assumption of a homogeneous set of high season transport routes. A constant load factor for the market is also assumed to be at $80 \%$, meaning that on average for each voyage $80 \%$ of capacity is filled. Depending on the load factor, the overall level of emissions per passenger increases or decreases but the general behaviour stays the same. The behaviour is due to two factors of fleet management: (1) There is an overall trend to lower emissions per passenger due to improvements in technology and (2) there are periodical increases of emissions caused by boat aging. It is assumed that due to wear and tear of the engine and other related boat characteristics the older boats operate at a lower efficiency and produce more emissions per passenger. The decreases in emissions comes from the increased building periods we have seen in objective 1 . There is no run without the implementation of the UIW tool shown as the differences in the emissions per passenger are only marginal

Table 5 Objective $4 \mathrm{~b}$ of the UIW Cluster 5 scorecard

\begin{tabular}{l|l}
\hline Name of the objective: Fuel saving (part b of the 4th objective) & Figure 21 \\
\hline Objective definition: Reduction of around $40 \%$ in the environmental footprint & \\
and resource consumption during the production and use phases of the meta & \\
products, together with an increased use of more environment-friendly materials & \\
\hline Cluster-specific objective: Ability to consider environment-friendly materials & \\
that could expand the life cycle of the product while decreasing the environmental & \\
footprint due to better forecast and planning (decrease of fuel consumption at & \\
approx. $€ 50-80 \mathrm{k} /$ year) &
\end{tabular}

Explanation: This objective addresses fuel savings due to improvements in material usage, technology and designs. The graph shows the UIW-target as a dashed line and the simulated result as a solid line. The simulation results show the comparison of the savings in any month compared to the same month a year ago. The savings are adjusted for market coverage, i.e., show the comparison if all passengers are served. There are some periods where operators do not have enough boats available to serve all passengers (between 2016 and 2021). This is also the period during which the largest yearly savings in fuel are realised. During this period a large number of boats are replaced with boats with a higher fuel efficiency and thus lead to fuel savings while also maxing out on the available capacity for boat construction and a backlog that causes the market to be underserved

setting of the model allows among other things to compare the effectiveness of upgrading strategies.

Regarding the Information Technologies (IT) support tools, the main limitations lay in the complexity of the tools (Snabe et al. 2006; Grossler 2004). 


\section{Conclusion and Future Work}

Building an industry model generated an important amount of information for strategic thinking and decision making to the cluster members. On one hand, it provided a clear link between the cluster activities, e.g., the development of the UIW tool and the UIW-objectives. On the other hand, it explicated the link between the individual and partially conflicting business objectives of the different market actors. One example is the boat lifetime which can be regulated by INSB. INSB's main concern for regulating the boat lifetime is safety, but at the same time it is a strong tool to manage the industry as a whole. SEAbility and OCEAN, however, have potentially conflicting objectives regarding the lifetime of boats. SEAbility requires the lifetime to be as long as possible as the initial purchase of the boat represents a significant investment. In particular, when it comes to converted small boats, the boat lifetime needs to be above twenty years to allow the effective and remunerative use of the small boats. On the other hand, OCEAN has an interest in shortening the lifetime of boats to increase replacement purchases although local optima exist where this causal relationship is reversed.

Overall, the model depicts the general dynamics of the ship-borne tourism industry in Greece and has been validated by market actors at the level of model structure and model behaviour. However, the lack of available data does not allow for a more in-depth calibration than the expert opinion of the cluster members. The difficulty in getting a clear set of data is that classifications, for example, include many other types of boats besides passenger boats, and thus during the model development it could not be identified which of the built boats are relevant for the model. In the end limited data sets for customer demand in Santorini were available as well as boat construction numbers for OCEAN. While the lack of data did not allow for modelling the actual development in the industry, the model provides value nonetheless by explicating the causal relationships between the different actors and markets and their respective dynamics. This allows users of the model to test possible outcomes of business decisions under any current circumstances.

The trade-off between the different market actors requires more research. In particular, the search for optima and their implications for operational safety will bring important insights for the management of the entire industry. Since this model has a strong focus on allocating the available resources of the boatyard and classification society equally between the different operators, it would be of interest to define more individual building and upgrading patterns for operators to allow for more detailed testing of the individual operator's strategies. Finally, the aspect of sustainability of boat replacements has not been addressed and could potentially alter the attractiveness of policies that shorten the boat lifetime. 


\section{References}

Redmine. (2006). http://www.redmine.org

Dubey, A., \& Wagle, D. (2007). Delivering software as a service. The McKinsey Quarterly, 6, 2007.

Groesser, S. N. (2012a). Mental models of dynamic systems. In N. M. Seel (Ed.), Encyclopedia of the sciences of learning. Heidelberg: Springer Science+Business Media.

Groesser, S. N. (2012b). Co-evolution of standards in innovation systems: The dynamics of voluntary and legal building codes, contributions to management science. Heidelberg: Springer.

Groesser, S. N., Schwaninger, M., et al. (2012). Contributions to model validation: Hierarchy, process, and cessation. System Dynamics Review, 28(2), 157-181.

Grossler, A. (2004). Don't let history repeat itself-Methodological issues concerning the use of simulators in teaching and experimentation. System Dynamics Review, 20(3), 263-274.

MoMM. (1979a). Rules Subdivision and Stability of vessels with LOA $<31 \mathrm{~m}$. Survey Department/Ministry of Merchant Marine.

MoMM. (1979b). Rules for surveying tourist passenger vessels. Survey Department/Ministry of Merchant Marine.

MoMM. (1988). Rules for surveying small work-boats. Survey Department/Ministry of Merchant Marine.

MoMM. (1996). Fire safety requirements for ships, Survey Department/Ministry of Merchant Marine.

MoMM. (2011). Rules for Accommodation of passenger vessels, Survey Department/Ministry of Merchant Marine.

SECP. (2000). Passenger vessels for the new Millenunium, Culnane, 2000, SECP Section Papers.

SNAAM. (1985). The small passenger vessel, Cashman 1985, Marine Technology, Society of Naval Architects and Marine Engineers.

Snabe, B., Grössler, A., et al. (2006). System dynamics modelling for strategy implementationCase study and issues. Systems Research and Behavioral Science, 23(4), 467-481.

SoNaME. (1990). Operation and cost of high speed craft, Wright, 1990 Marine Technology, Society of Naval Architect and Marine Engineers.

Open Access This chapter is licensed under the terms of the Creative Commons Attribution-NonCommercial 4.0 International License (http://creativecommons.org/licenses/by-nc/ 4.0/), which permits any noncommercial use, sharing, adaptation, distribution and reproduction in any medium or format, as long as you give appropriate credit to the original author(s) and the source, provide a link to the Creative Commons license and indicate if changes were made.

The images or other third party material in this chapter are included in the chapter's Creative Commons license, unless indicated otherwise in a credit line to the material. If material is not included in the chapter's Creative Commons license and your intended use is not permitted by statutory regulation or exceeds the permitted use, you will need to obtain permission directly from the copyright holder.

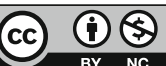

